\title{
Perinatal mortality and socio-spatial inequalities ${ }^{1}$
}

\author{
Eunice Francisca Martins ${ }^{2}$ \\ Edna Maria Rezende ${ }^{3}$ \\ Maria Cristina de Mattos Almeida ${ }^{4}$ \\ Francisco Carlos Félix Lana ${ }^{3}$
}

Objective: to analyze the social inequalities in the distribution of perinatal mortality in Belo Horizonte. Material and methods: the perinatal deaths of residents in Belo Horizonte in the period 2003 to 2007 were studied on the basis of the Information Systems on Mortality and Newborns. The space analysis and the Health Vulnerability Index were used to identify existing inequalities in the sanitary districts regarding coverage and risk, determined by the Odds Ratio and a value $p<0.05$. The multivariate analysis was used to describe a model for perinatal mortality. Results: there was a proved variation in the numbers of perinatal mortality per one thousand total births in the sanitary districts (12.5 to 19.4 ), coverage areas (5.3 to 49.4 ) and areas of risk (13.2 to 20.7). The mortality rate diminished as the maternal schooling increased. The death rates deriving from asphyxia/hypoxia and non-specified fetal death grew with the increase of risk in the area. Conclusion: it was verified that the perinatal deaths are distributed in a differentiated form in relation to the space and the social vulnerabilities. The confrontation of this complex problem requires the establishment of intersecting partnerships.

Descriptors: Perinatal Mortality; Health Inequalities; Residence Characteristics; Public Health Nursing.

\footnotetext{
${ }^{1}$ Paper extracted from doctoral dissertation presented to "Mortalidade perinatal e avaliação da assistência ao pré-natal, ao parto e ao recémnascido, Belo Horizonte, Minas Gerais" presented to Escola de Enfermagem, Universidade Federal de Minas Gerais, Belo Horizonte, MG, Brazil. Supported by Fundação de Amparo à Pesquisa do Estado de Minas Gerais (FAPEMIG) process \# CDS - APQ-00901-08.

2 PhD, Adjunct Professor, Escola de Enfermagem, Universidade Federal de Minas Gerais, Belo Horizonte, MG, Brazil. ${ }^{3} \mathrm{PhD}$, Associate Professor, Escola de Enfermagem, Universidade Federal de Minas Gerais, Belo Horizonte, MG, Brazil. ${ }^{4}$ MSc, Veterinarian, Secretaria Municipal de Saúde de Belo Horizonte, Belo Horizonte, MG, Brazil.
} 


\section{Introduction}

The health-disease process is a complex phenomenon, determined through biological, environmental and social questions. In the last decades, with the discussion on development objectives of the millennium, the relation between health and social determinatives stood out in the analysis of the health and illness process of the individuals and the population $^{(1)}$. In accordance with the World Health Organization (WHO), social determinatives of health $(\mathrm{SDH})$ are to be understood as set of the conditions in which people live and work. These conditions derive from the socioeconomic-political context and generate social stratifications and inequalities in health(2).

The epidemiological studies use, besides the social aspects, the spatial analysis to recognize the influence of the space in the exposition differentials and inequalities in the process of morbidity-mortality in the collective ${ }^{(3-5)}$. This technique allows to elaborate the explanatory chain of the health-disease process on the basis of the reality in the territory and to direct the necessity of policies and intersecting actions $^{(6)}$. These policies must aim at the reduction of the inequalities generated through the social determinatives of health(1), with actions that promote alterations in the collective context and not only in the individual one.

In the case of perinatal mortality, the determinative rights are the biological factors - low birth weight and prematurity ${ }^{(7-8)}$. However, other aspects as the maternal health condition, the access and the quality of the health services, the socio-economic situation and the environment where the individual lives may interfere with the causal chain of these deaths ${ }^{(7,9)}$. As a result of the social, economic and technological inequalities, disparities in the levels and causes of perinatal deaths between the regions are observed. In the developed countries, these deaths are a rare incident, whereas they are very common in the poor countries and little attention is given to them. Almost the totality of the perinatal deaths is concentrated in the lesser developed regions(10), where the decline of these deaths occurs in a slow form, even with the availability of several technologies and effective interventions for its prevention ${ }^{(11-12)}$. The great worldwide challenge is, therefore, to make such interventions accessible to the most vulnerable populations.

In Brazil, the presence of inequalities in the indicators for maternal and infantile health was verified by the National Commission for Social Determinatives of Health that identified inequalities in the indicators regarding access to health services, mortality and morbidity, according to the social background. The worst indicators were observed for the groups that live in unfavorable

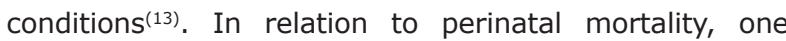
of the most relevant inequalities is the non-availability of the mortality rate from all the states and regions of the country, due to the limitations in the information system. This indicator is available only for the southern region, some states of the southeastern region and for the Federal District and varies from 15.0 to 20.0 per one thousand live births (LB's) and still births (SB's) ${ }^{(14)}$.

In the city Belo Horizonte, the perinatal mortality rate has been declining, especially in its precocious neonatal component, reaching in 200914.3 deaths per one thousand total births. This rate was similar to the one of the Federal District and other states of the southeastern region ${ }^{(14)}$, but still with potential for further reduction awaiting the perinatal attendance network to be installed in the city and in relation to the already reached levels in other countries, like Argentina (10.8), United States (9.6), Spain (4.5) and the United kingdom $(7.6)^{(11-12,15)}$. There are also social and spatial differences in perinatal mortality, as already evidenced for infantile mortality in the city(4). Thus, this study was proposed with the objective to analyze the inequalities in perinatal mortality in the city Belo Horizonte, based on the spatial distribution of the deaths and the use of a health vulnerability indicator. The results can support the planning of preventive measures aimed at priority areas according to the unequal risk distribution.

This study also contributes to deepen the discussion on spatial inequalities and social vulnerabilities in perinatal mortality, since the majority of the studies of this sort focuses only on infantile mortality and the health indicators for the woman and the child(4,16-17). Understanding the perinatal death in relation to the living conditions in which the expectant mother was inserted itself extends the knowledge of the health professionals in the comprehension of this complex phenomenon ${ }^{(18)}$.

\section{Material and methods}

This is an ecological study on the basis of perinatal deaths data of residents in Belo Horizonte, occurring in the period from 2003 to 2007 . The data were originating from the Information System on Mortality (ISM) and from the Information System on Live Births (Sinasc), supplied by the Local Health Authority Belo Horizonte (SMSA-BH). The use of these banks was necessary for the access to information of the georeferencing, not 
contained in the available banks online in the site of the Informatics Department from SUS (Datasus).

SIM supplied the data related to the deaths and the Sinasc, the numbers of the live births, used as denominator for the calculation of the perinatal mortality rate. The included variables in the study were all originating from SIM. The basic causes of the deaths were grouped according to a list reduced to the tabulation of the causes of neonatal deaths ${ }^{(19)}$. This tabulation includes the detailed breakdown of the causes of death by means of related codes in order to direct preventive health measures. The further variables were: type of death (fetal and neonatal precocious); maternal schooling by years of study (none, 1-3, 4-7, 8-11, 12 and more); sanitary district of the residence (Center-South, Barreiro, East, Northeast, Northwest, North, West, Pampulha and Venda Nova); coverage area of the Health Authority and risk classification of the mother's residence area.

The used risk classification was the one from the Health Vulnerability Index (IVS) from the City Health Department Belo Horizonte. The classification of the IVS was elaborated with the objective to map the risk areas of the city in order to direct the health measures. The IVS is a composed indicator that synthesizes different socioeconomic and environmental variables, considered essential to reach the citizens, namely: sanitation, habitation, education, income and social/health. 13 indicators are used, with differentiated weighting in each dimension. The final value of the IVS varies between 0 (zero) and one and is applied in each census sector of the city. The higher the IVS value, the worse the condition of the population in the sector. It was established, an intraurban hierarchization of spatial units, defined in four risk classes: low, medium, high and very high(20).

The city Belo Horizonte uses the IVS associated to the process of division into districts for the construction of the health attention model. This process incorporates the spatial insertion of the population in a given territory, resulting from different economic and productive processes that cause differences in the life and death conditions. The city is divided into nine Sanitary Districts (SD's) and each one of them possesses 15 to 20 Health Centers, with delimited coverage areas, composed by a set of census sectors(21). Thus, a spatial and sectoral diagnosis of the problems and priorities is possible.

The properties of the perinatal mortality rates in the period were evaluated by means of components, and the inequalities in the distribution of the mortality rates per DS, coverage areas and health vulnerability areas. The inequalities in the distribution of the mortality rates between the DSs and health vulnerability areas were verified through Odds Ratio/Reason of Possibilities Odds Ratio/Razão de Chances and the value of $\mathrm{p}$ at a significance level of 5.0\%, using the Epi info software, version 10 . The MapInfo software was used for the elaboration of the thematic maps. The logistic regression was accomplished to evaluate the effects of the following variables: risk of the mother's residence area, maternal schooling and the interaction of both regarding perinatal mortality.

The project was approved by the Ethics Committees of the Federal University Minas Gerais on 5 June 2008, under Decree no 242/08, and by the City Health Department Belo Horizonte under Decree no 042/2008.

\section{Results}

In the studied period, there were 2,710 perinatal deaths of residents in the city Belo Horizonte registered. Of these, $1,693(62.5 \%)$ were fetal and 1,017 precocious neonatal. In Figure 1 , the decline of the perinatal mortality rate and its components in the period is presented, but the reduction was only statistically significant $(p<0.05)$ for the precocious neonatal deaths.

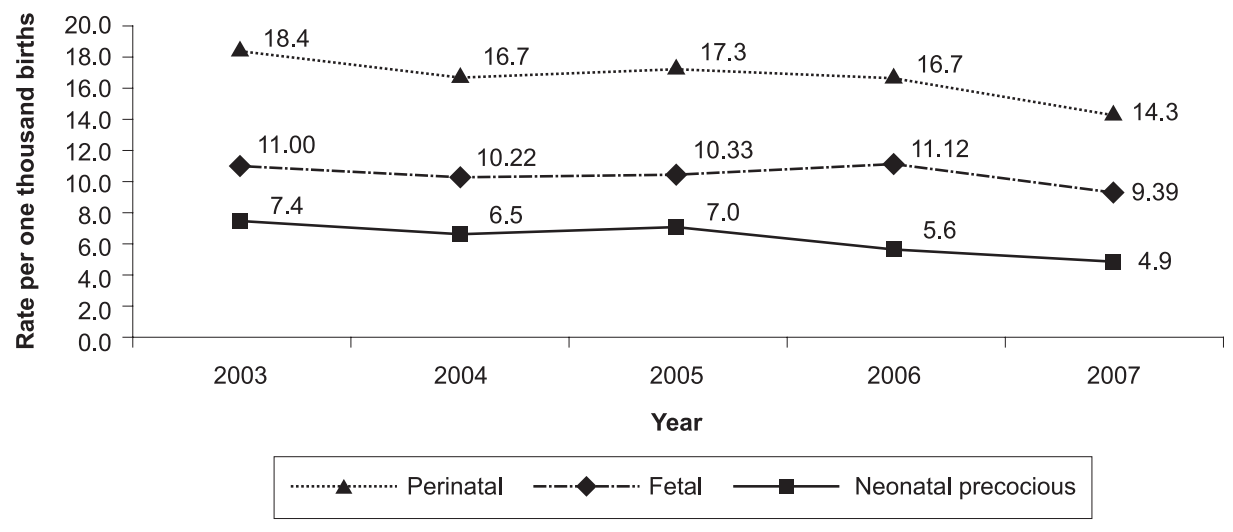

Source: Information System on Mortality. City Health Department Belo Horizonte

Figure 1 - Perinatal mortality rates by years and components. Belo Horizonte, MG, Brazil, 2003-2007 
In Figure 2, the distribution of the perinatal mortality for the nine DSs of the city is presented. The most elevated rate was registered in the DS the Northwest
(19.4) and the least elevated one in the DS Pampulha (12.5), with a statistically significant difference ( $p<$ $0.05)$ in relation to the other districts of the city.

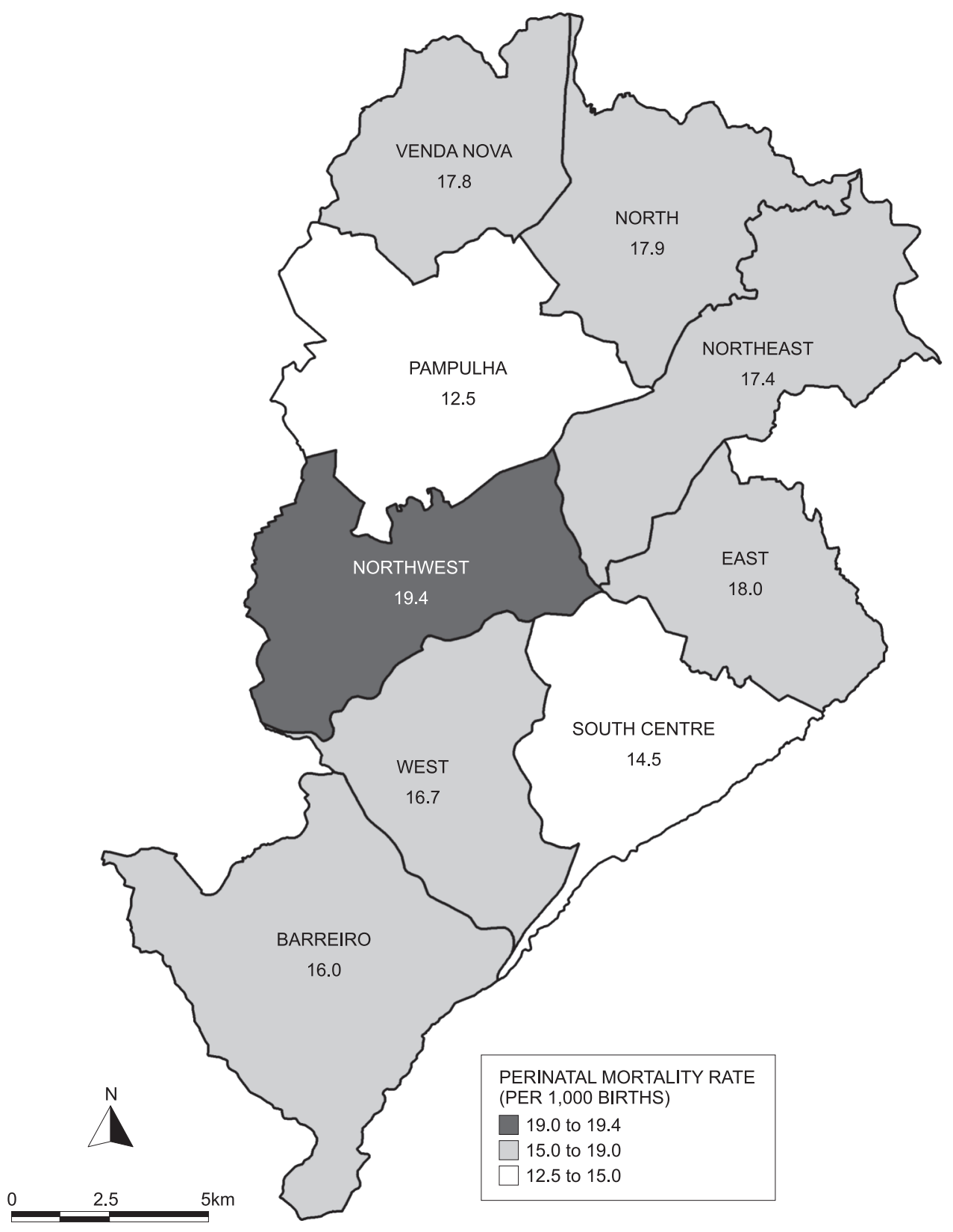

Source: Information System on Mortality. City Health Department Belo Horizonte

Figure 2 - Perinatal mortality distribution rate map per sanitary district. Belo Horizonte, MG, Brazil, 2003-2007

In Figure 3, it is shown that the perinatal mortality rates per coverage areas varied from 5.3 to 49.4 per one thousand total births. The lowest rates of 11.1 (first quartile) were concentrated in 20 coverage areas and represented $14.3 \%$ of the total. The highest rates, above 22.1 (last quartile), totalized $12.9 \%$ and were registered in 18 areas. The rates comprised between 11.1 and 22.1, observed in 102 areas, represented $72.8 \%$ of the total. 


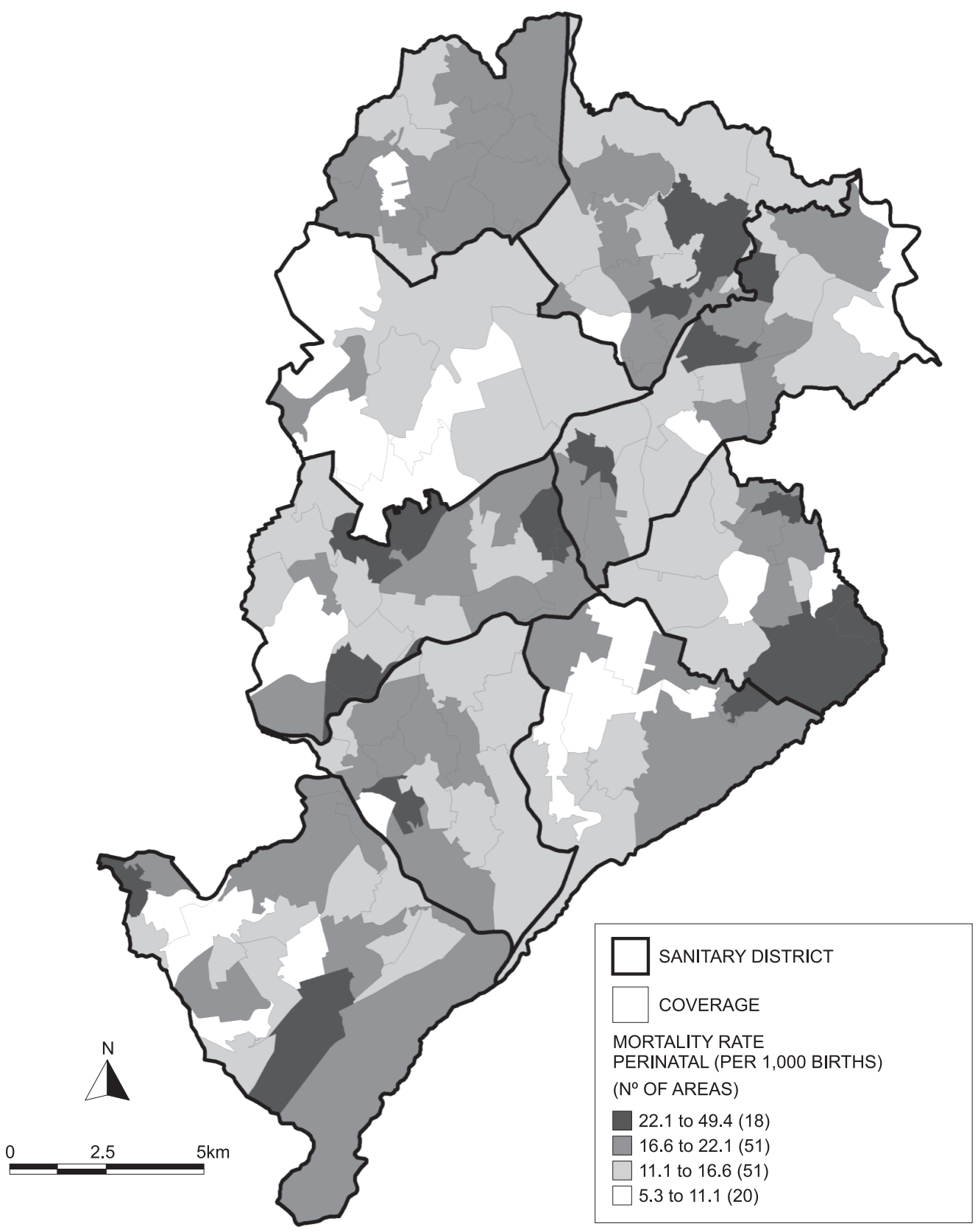

Source: Information System on Mortality. City Health Department Belo Horizonte

Figure 3 - Spatial distribution map regarding perinatal mortality rate per coverage area. Belo Horizonte, MG, Brazil, 2003-2007

In Table 1, the final model for perinatal mortality is presented. It is to observe that the risk area variables and the maternal schooling were significant, having an interaction between both. The risk of perinatal death was increasing with the increase of risk in the residence area and decreasing with the increase of the maternal schooling. Significance for all the terms of the final regression model and all the possible interactions was evidenced.

In relation to the main groupings of causes for perinatal death, the rates presented statistically significant and increasing variations with the increase of the area risk for the fetal death through non-specified cause and asphyxia/hypoxia (Table 2). 
Table 1 - Logistic regression model for perinatal mortality according to schooling of the mother, area risk and the interaction between these two variables. Belo Horizonte, MG, Brazil, 2003-2007

\begin{tabular}{|c|c|c|c|}
\hline Variables & $\begin{array}{l}\text { Coefficients of the } \\
\text { regression model }(\beta)\end{array}$ & Value-p & $\begin{array}{l}\text { Odds Ratio } \\
\text { (IC 95\%) }\end{array}$ \\
\hline \multicolumn{4}{|l|}{ Area risk ${ }^{*}$} \\
\hline Medium & 1.3 & 0.000 & $3.7(2.7-5.1)$ \\
\hline High & 2.2 & 0.000 & $9.4(6.8-13.0)$ \\
\hline Very High & 3.0 & 0.000 & $20.9(13.7-32.0)$ \\
\hline \multicolumn{4}{|l|}{ Maternal schooling ${ }^{\dagger}$ (years) } \\
\hline None & 4.1 & 0.000 & $60.7(28.4-129.9)$ \\
\hline 1 to 3 & 2.5 & 0.000 & $11.9(6.8-21.0)$ \\
\hline 4 to 7 & 2.7 & 0.000 & $14.5(10.5-20.0)$ \\
\hline 8 to 11 & 1.5 & 0.000 & $4.5(3.3-6.1)$ \\
\hline \multicolumn{4}{|l|}{ Interaction schooling and area risk ${ }^{\ddagger}$} \\
\hline None and medium risk & -1.2 & 0.007 & $0.3(0.1-0.7)$ \\
\hline None and high risk & -2.5 & 0.000 & $0.1(0.0-0.2)$ \\
\hline None and very high risk & -4.6 & 0.000 & $0.0(0.0-0.0)$ \\
\hline 1 to 3 years and medium risk & -1.5 & 0.000 & $0.2(0.1-0.4)$ \\
\hline 1 to 3 years and high risk & -3.0 & 0.000 & $0.0(0.0-0.1)$ \\
\hline 1 to 3 and very high risk & -4.3 & 0.000 & $0.0(0.0-0.0)$ \\
\hline 4 to 7 years and medium risk & -2.2 & 0.000 & $0.1(0.1-0.2)$ \\
\hline 4 to 7 years and high risk & -3.6 & 0.000 & $0.0(0.0-0.0)$ \\
\hline 4 to 7 years and very high risk & -4.4 & 0.000 & $0.0(0.0-0.0)$ \\
\hline 8 to 11 years and medium risk & -1.5 & 0.000 & $0.2(0.2-0.3)$ \\
\hline 8 to 11 years and high risk & -2.3 & 0.000 & $0.1(0.1-0.1)$ \\
\hline 8 to 11 years and very high risk & -2.9 & 0.000 & $0.1(0.0-0.1)$ \\
\hline Constant $\left(\beta_{0}\right)$ & -5.7 & 0.000 & \\
\hline
\end{tabular}

* Reference category: Low risk

† Reference category: 12 or more years

₹ Reference category: Low risk and 12 or more years of schooling

Source: Information System on Mortality/City Health Department Belo Horizonte

Table 2 - Distribution of the perinatal mortality rate according to risk areas and main groupings of death causes. Belo Horizonte, MG, Brazil, 2003-2007

\begin{tabular}{|c|c|c|c|c|c|}
\hline \multirow{2}{*}{$\begin{array}{c}\text { Cause } \\
\text { grouping }\end{array}$} & \multicolumn{5}{|c|}{ Area Risk } \\
\hline & Low & Medium & High & $\begin{array}{l}\text { Very } \\
\text { high }\end{array}$ & $p$ value \\
\hline $\begin{array}{l}\text { Fetal death } \\
\text { non-specified }\end{array}$ & 1.99 & 3.13 & 3.69 & 4.99 & 0.001 \\
\hline Asphyxia/Hypoxia & 2.61 & 3.47 & 3.81 & 4.15 & 0.03 \\
\hline Prematurity & 2.21 & 2.07 & 2.20 & 2.33 & 0.734 \\
\hline $\begin{array}{l}\text { Congenital } \\
\text { malformation }\end{array}$ & 1.68 & 1.60 & 1.97 & 1.91 & 0.738 \\
\hline
\end{tabular}

Source: Information System on Mortality. City Health Department Belo Horizonte

\section{Discussion}

The perinatal mortality rates and the trend of decline found in this study were similar to the rates in the states of the southern region in Brazil and in São Paulo(14). The reduction of perinatal mortality in the city is a positive fact that is most likely attributable to the implementation of improvements in the perinatal attention. The structure of the Perinatal Commission, a permanent, deliberative and managing forum for the assistance policies for pregnant women and newborns, has contributed to the improvement of the quality and favored the completeness of the actions in this area(15).

The predominance of the fetal component in the perinatal mortality observed in this study is consensus in literature, especially among the countries that have already reached lower perinatal mortality rates ${ }^{(8,10)}$. The excess of fetal deaths in relation to the precocious neonatal in perinatal mortality can be explained through the bigger decline of neonatal mortality, the lower attention to the prevention of these deaths in the last decades and the greater difficulty in reducing the fetal deaths, especially since many of these deaths are inexplicable ${ }^{(7-8,10)}$. The reduction of the fetal deaths is still a great challenge for the health services and professionals. In this aspect, the role of the Death Prevention Committees in the investigation and monitoring of these deaths stands out. The Death Prevention Committee Belo Horizonte, one of the pioneers in the country, has, since 2002, been investigating the infantile and fetal deaths for a better understanding of the effective situation and 
identification of the points of shortage throughout the care. This has given a bigger visibility regarding these deaths and allowed for advances in the strategies for a reduction of perinatal mortality in the city ${ }^{(15)}$. It is to distinguish that the nurse is one of the professionals acting in the Central Committee, the District Committees and participating effectively in the investigations in the health services and the home, besides the discussion of these cases for a proposal of preventative measures at several assistance levels of the perinatal network of the city.

The perinatal mortality rate was similar in the majority of the DSs of Belo Horizonte, in virtue of being extensive territories and grouping in the one same space distinct areas, whose average rate does not reflect the socioeconomic inequalities. In a similar study on infantile mortality in the city, accomplished in the 1990's, great inequalities in the mortality rates in these areas were not evidenced ${ }^{(4)}$. The lower perinatal mortality rates, found in the DSs Center-South and Pampulha were expected, as these regions concentrate the lower percentile of population living in areas of high and very high risk in the city(21). However, the highest average rate for the DS Northwest was not expected, since this region presents a percentile of population living in areas of high risk similar to the districts with lower rates. This finding reinforces the necessity of an analysis more directed toward the micro-areas.

The differences in the observed perinatal mortality rates between the coverage areas are most likely originated in the fact of being smaller and more homogeneous territories, allowing for substantiating the existing differences in the average rates. A similar situation had already been evinced in Belo Horizonte for infantile mortality ${ }^{(4)}$. The analysis per coverage area allows that each team of the Health Centers knows the situation regarding mortality where it acts and adopts intervention measures based on the local reality.

The association of a bigger perinatal mortality risk for the population living in areas of poverty concentration found in Belo Horizonte was similar to the situation already identified in other studies on neonatal and infantile mortality ${ }^{(3-5)}$. This means that the social conditions where one lives can even affect the intrauterine life and that it is important to understand the determinatives of perinatal mortality go beyond the biological factors. Therefore, special attention must be directed to the residents of areas with higher social vulnerability that alone concentrate already many unfavorable conditions for the infantile survival.
The low maternal schooling was the condition for the biggest risk for perinatal mortality, and even in the areas of low risk the women in this condition had a greater probability of losses. Similar findings were identified in national studies ${ }^{(9)}$ and also in developed countries that present low perinatal mortality rates ${ }^{(5,7-8)}$. Mothers with few years of study tend to have worse socioeconomic conditions and higher vulnerability to risk situations, which intervene in the fetal and infantile survival. Therefore, the women in this condition ought to be attended in a differentiated form to reduce the health inequity deriving from their circumstances of life, as well as to be directed to the existing agencies of social support.

The fetal death through non-specified cause, with rates increasing in a significant form with the increase of the risk in the area can be resulting from several factors, amongst which are bad fetal nutrition, chromosomal aberrations, infections and maternal diseases(7,22). Thus, women living in areas of bigger vulnerability may have not been adequately accompanied in the prenatal period, reflecting in the non-diagnosis of some grievance for the specification of the fetal death.

The increasing risk of perinatal death through asphyxia/hypoxia, found in the areas of bigger health vulnerability, can be related to the quality of the prenatal and childbirth assistance, as well as the adverse health conditions and unfavorable life of the expectant mothers. A similar situation was identified in a study in India, where the determinatives of perinatal mortality through asphyxia were related to the low socioeconomic level and the inadequate assistance in the prenatal period and the childbirth, especially through the cares provided by non-qualified staff(23). These deaths are, in their majority, evitable and their reduction constitutes a great challenge, mainly for the poorer countries, where human resources and technology for an adequate assistance lack(11). The mortality rates deriving from asphyxia are therefore a sensible indicator for the quality of the assistance during the delivery process and the birth ${ }^{(11)}$. In the case of Belo Horizonte, that already has an ample service network for perinatal attention, regionalized and graduated by complexity levels, at its disposal, this situation shows the necessity of better qualification in these services, including the approach of the social health determinatives.

The use of secondary data for the elaboration of sensible indicators for the health inequalities is limited through the availability and quality of the existing

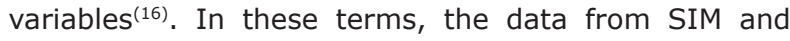
Sinasc Belo Horizonte were considered satisfactory with regard to their completeness. It is to point out that for 
the planning of the health services, the use of the vital statistics is important and necessary, and ergo, the improvement of its quality must be continuous.

\section{Final considerations}

It is certified that the perinatal mortality rate in Belo Horizonte is in decline and that the perinatal deaths are distributed in a differentiated form in relation to the space and the social vulnerabilities existing there. The inequalities were verified in the distribution of the deaths by DSS, coverage areas and risk areas. The increase of the perinatal mortality rates showed direct relation with the increase of risk of the area and inverse with the rise of the schooling of the mother. There was interaction between these variables, being that the low maternal schooling increases the risk of perinatal death in all the areas. It was also observed that deaths through evitable causes, like asphyxia/hypoxia, more related to the quality of the assistance in the prenatal period and to the childbirth, show higher rates in the areas of higher social vulnerability. Thus, it is important to understand that the determinatives of perinatal mortality go beyond the classic biological factors, including the social and environmental context in this process.

The spatial analysis of perinatal mortality proves to be a useful tool to support the health services in identifying areas that require a differentiated approach, aimed at correcting the socio-spatial inequalities. The used Health Vulnerability Indicator was capable to collect social differences in perinatal mortality. However, other social aspects can be included in future studies, such as the health conditions, life and work of the expectant mother and the of available support network in the community for the confrontation of the social vulnerabilities. Continuous monitoring of the sociospatial distribution of mortality for the planning of the health interventions and the evaluation of the impact of public policies in the reduction of mortality and health inequities in areas of higher risk are recommended.

The identified situation requires from the health services an extended vision, dislocating the focus of attention from the exclusive axis for the health recovery of sick individuals to the risk prevention and health promotion for the people and population groups. In this sense, work in a multi-professional team, integration with other services and establishment of intersectional partnerships become necessary. Finally, it has been distinguished that the nurse, given the insertion in several areas of the assistance and the management of the health services, is capable to articulate actions that contribute to the reduction of the health inequities and foster greater fetal and infantile survival.

\section{References}

1. Buss PM, Pellegrini FA. A Saúde e seus Determinantes Sociais. Physis. 2007 jan-abr;17(1):77-93.

2. World Health Organization. A conceptual framework for action on the social determinants of health. Social Determinants of Health Discussion Paper 2 (Policy and Practice). Geneva; 2010. 79 p.

3. Gonçalves AC, Costa MCN, Braga JU. Análise da distribuição espacial da mortalidade neonatal e de fatores associados, em Salvador, Bahia, Brasil, no período 20002006. Cad Saúde Pública. 2011;27(8):1581-92.

4. Malta DC, Almeida MCM, Dias MAS, Merhy EE. A mortalidade infantil em Belo Horizonte, Minas Gerais, Brasil, por área de abrangência dos Centros de Saúde (1994-1996). Cad Saúde Pública 2001 setout; $17(5): 1189-98$.

5. Mortensen LH, Helweg-Larsen K, Andersen AN. Socioeconomic differences in perinatal health and disease. Scand J Public Health. 2011;39(Suppl 7):110-4. 6. Hino P, Villa TCS, Sassaki CM, Nogueira JA, Santos CB. Geoprocessing in Health Area. Rev. Latino-Am. Enfermagem. 2006;14(6):939-43.

7. Centre for Maternal and Child Enquiries (CMACE) Perinatal Mortality 2009: United Kingdom. CMACE: London: CMACE; 2011.

8. Macdorman MF, Kirmeyer S, Wilson EC. Fetal and Perinatal Mortality, United States, 2006. Hyattsville, MD: National Center for Health Statistics; 2012. 23 p. (National vital statistics reports, v. 60, n. 8)

9. Lansky S, França E, Kawachi IS. Social inequalities in perinatal mortality in Belo Horizonte, Brazil: the role of hospital care. Am J Public Health. 2007;97(5):867-73.

10. World Health Organization. Neonatal and perinatal mortality: country, regional and global estimates. Geneva: WHO; 2006. World Health Report 2006. 75 p.

11. Lozano $R$, Wang $H$, Foreman $\mathrm{KJ}$, Rajaratnam JK, Naghavi M, Marcus JR, et al. Progress towards millennium development goals 4 and 5 on maternal and child mortality: an updated systematic analysis. Lancet. 2011;378:1139-65.

12. Cousens $S$, Blencowe $H$, Stanton C, Chou D, Ahmed S, Steinhardt $L$, et al. National, regional, and worldwide estimates of stillbirth rates in 2009 with trends since 1995: a systematic analysis. Lancet. 2011;377(9774):1319-30. 
13. Comissão Nacional sobre Determinantes Sociais da Saúde. As Causas Sociais das Iniqüidades em Saúde no Brasil. Rio de Janeiro: Fiocruz; 2008. 220 p.

14. Ministério da Saúde (BR). Secretaria de Vigilância em Saúde. Departamento de Análise de Situação de Saúde. Vigilância em Saúde: dados e indicadores selecionados. Brasília; 2011. [acesso 11 nov 2012]; Disponível em: <http://tabnet.datasus.gov.br/cgi/idb2011/matriz.htm> 15. Lansky S. Gestão da qualidade e da integralidade do cuidado em saúde para a mulher e a criança no SUS-BH: a experiência da comissão perinatal. Rev Tempus Actas Saude Col. 2010;4(4):191-9.

16. Melo EC, Mathias TAF. Spatial Distribution and SelfCorrelation of Mother and Child Health Indicators in the State of Parana, Brazil. Rev. Latino-Am. Enfermagem. 2010;18(6):1177-86.

17. Barria-Pailaquilen RM, Mendonza-Maldonado $Y$, Urrutia-Toro Y, Castro-Mora C, Santander-Manríquez. Trends in Infant mortality rate and mortality for neonates born at less than 32 weeks and with very low birth weight. Rev. Latino-Am. Enfermagem 2011;19(4):977-84.

18. Montero SMP, Sánchez JMR, Montoro CH, Crespo ML, Jaén AGV, Tirado MBR. Experiences with perinatal loss from the health professionals' perspective. Rev. LatinoAm. Enfermagem 2011;19(6):1405-12.

19. França E, Lansky S. Mortalidade infantil neonatal no Brasil: situação, tendências e perspectivas. In: Rede Interagencial de Informações para Saúde-Ripsa. Demografia e Saúde: contribuição para análise de situação e tendências. Brasília: DF; 2009. p. 83-112

20. Secretaria Municipal de Saúde de Belo Horizonte (BR). Gerência de Epidemiologia e Informação - GEEPI. Índice de Vulnerabilidade à Saúde 2003. [acesso 10 jan 2012]; Disponível em: http://www.pbh.gov.br/smsa/ biblioteca/mostraarquivo.php.

21. Secretaria Municipal de Saúde de Belo Horizonte (BR). Sistema Único de Saúde. Relatório de Gestão 2008. 2009. [acesso 10 jan 2012]; Disponível em: http://www.portalpbh.pbh.gov.

22. Lawn JE, Blencowe $H$, Pattinson R, Cousens $S$, Kumar R, Ibiebele I, et al. Stillbirths: Where? When? Why? How to make the data count? Lancet. $2011 ; 377$ (9775): 1448-63.

23. Rani S, Chawla D, Huria A, Jain S. Risk factors for perinatal mortality due to asphyxia among emergency obstetric referrals in a tertiary hospital. Indian Pediatr. 2012;49:191-4. 